\title{
Efficacy comparison of ramosetron with ondansetron on preventing nausea and vomiting in high-risk patients following spine surgery with a single bolus of dexamethasone as an adjunct
}

\author{
Yong Seon Choi ${ }^{1,2}$, Jae-Kwang Shim ${ }^{1,2}$, Seung-Ho Ahn ${ }^{1}$, and Young Lan Kwak ${ }^{1,2}$ \\ ${ }^{1}$ Department of Anesthesiology and Pain Medicine, ${ }^{2}$ Anesthesia and Pain Research Institute, Yonsei University College of Medicine, \\ Seoul, Korea
}

Background: Despite the development of a new class of antiemetics, postoperative nausea and vomiting (PONV) still remains a frequent and distressing complication. We compared the prophylactic antiemetic effect of administering dexamethasone $5 \mathrm{mg}$ as an adjunct to ramosetron and ondansetron in patients at high-risk for PONV following lumbar spinal surgery.

Methods: In this randomized, double-blind study, 120 female non-smoking patients with intravenous patientcontrolled analgesia (PCA) received ramosetron $0.3 \mathrm{mg}$ plus dexamethasone $5 \mathrm{mg}$ (group $\mathrm{R}+\mathrm{D}$ ) or ondansetron $4 \mathrm{mg}$ plus dexamethasone $5 \mathrm{mg}$ (group $\mathrm{O}+\mathrm{D}$ ) intravenously. Fentanyl-based PCA was administered for $48 \mathrm{hr}$ postoperatively; ramosetron $0.3 \mathrm{mg}$ or ondansetron $12 \mathrm{mg}$ was added to the PCA regimen according to the allocated group. The incidence of PONV and rescue antiemetic were assessed for $48 \mathrm{hr}$ postoperatively at $0-6,6-24$, and $24-$ $48 \mathrm{hr}$.

Results: The overall incidence of PONV did not differ between the groups ( $50 \%$ vs. $60 \%$, in groups R + D and O + D, respectively). The overall incidence of nausea was similar between groups ( $47 \%$ vs. $60 \%$, in groups $\mathrm{R}+\mathrm{D}$ and $\mathrm{O}+\mathrm{D}$, respectively). The overall frequency of vomiting was also similar between groups ( $8 \%$ vs. $12 \%$, in groups $\mathrm{R}+\mathrm{D}$ and $\mathrm{O}$ $+\mathrm{D}$, respectively). The severity of nausea and the overall use of rescue antiemetic were not different between groups. Conclusions: The antiemetic efficacy of ramosetron plus dexamethasone was similar to that of ondansetron plus dexamethasone on preventing PONV in high-risk patients undergoing lumbar spinal surgery. (Korean J Anesthesiol 2012; 62: 543-547)

Key Words: Dexamethasone, Ondansetron, Postoperative nausea and vomiting, Ramosetron.

Received: September 8, 2011. Revised: 1st, October 27, 2011; 2nd, November 18, 2011. Accepted: November 18, 2011.

Corresponding author: Young Lan Kwak, M.D., Ph.D., Department of Anesthesiology and Pain Medicine, Anesthesia and Pain Research Institute, Yonsei University College of Medicine, 250, Seongsan-no, Seodaemun-gu, Seoul 120-752, Korea. Tel: 82-2-2228-8514, Fax: 82-2-3642951, E-mail: ylkwak@yuhs.ac

(c) This is an open-access article distributed under the terms of the Creative Commons Attribution Non-Commercial License (http:// creativecommons.org/licenses/by-nc/3.0/), which permits unrestricted non-commercial use, distribution, and reproduction in any medium, provided the original work is properly cited. 


\section{Introduction}

Postoperative nausea and vomiting (PONV) is a frequent and distressing condition which undoubtedly exerts adverse influences on patients' satisfaction and recovery as well as resource utilization and health care costs [1]. Accordingly, effective therapeutic interventions should be sought and considered to prevent PONV, especially in patients with several risk factors for PONV, such as the female gender, nonsmoking, prior history of motion sickness or PONV, and the use of postoperative opioids [2,3]. In patients undergoing lumbar spinal surgery, patient-controlled analgesia (PCA) using intravenous opioid is a common and effective method with a high satisfaction rate for postoperative pain control; however, it is associated with a high incidence of PONV, exceeding 60\% [4].

Considering the multifactorial nature of PONV and the evidence suggesting limited efficacy of a single antiemetic treatment, combination of antiemetics from different classes is more effective in preventing PONV in patients at moderate to severe risk $[2,5]$. 5-hydroxytryptamine receptor $3\left(5-\mathrm{HT}_{3}\right)$ antagonists are frequently used, and among these, ramosetron is a newly developed $5-\mathrm{HT}_{3}$ antagonist with higher receptor affinity and a longer duration of action than its congeners, such as ondansetron and granisetron [6-8]. Dexamethasone has been successfully used as an adjunct to $5-\mathrm{HT}_{3}$ antagonists, resulting in enhanced antiemetic efficacy with negligible side effects [9-12]. Although ramosetron demonstrated promising results in recent studies for preventing PONV compared to ondansetron in highrisk patients $[6,7]$, the antiemetic efficacies of these two individual $5-\mathrm{HT}_{3}$ antagonists with dexamethasone in patients at high risk for PONV have not yet been evaluated.

Therefore, we designed this prospective, randomized, double-blind study to compare the antiemetic efficacy of ramosetron plus dexamethasone for preventing PONV to that of ondansetron plus dexamethasone in highly susceptible patients receiving intravenous PCA undergoing lumbar spinal surgery during the first postoperative 48 hours.

\section{Materials and Methods}

After approval of the institutional review board and obtaining informed consent from the patients, we studied 120 ASA physical status I and II patients aged 20 to 65 years who were scheduled for elective lumbar spinal surgery. The inclusion criteria were patients who had three predictors according to the simplified risk score for PONV by Apfel et al. [3]: female gender, non-smoker, and postoperative opioid use. Patients were excluded from the study for the following reasons: administration of antiemetic medication within $24 \mathrm{hr}$ before surgery, administration of steroids within $24 \mathrm{hr}$ before surgery or during
$48 \mathrm{hr}$ after surgery, history of gastrointestinal disease, opioid dependence, diabetes mellitus, obesity (body mass index $\geq 35$ $\mathrm{kg} / \mathrm{m}^{2}$ ), and impaired renal or hepatic function.

On the day of surgery, patients were randomly assigned by a computer-generated table of random numbers to receive ramosetron plus dexamethasone (group $\mathrm{R}+\mathrm{D}$ ) or ondansetron plus dexamethasone (group $\mathrm{O}+\mathrm{D}$ ). Upon arrival at the operating room, standard monitoring devices were applied. Before the induction of anesthesia, dexamethasone $5 \mathrm{mg}$ was given intravenously in both groups. Anesthesia was induced with $1.5-2.5 \mathrm{mg} / \mathrm{kg}$ propofol and $0.5-1 \mu \mathrm{g} / \mathrm{kg}$ remifentanil, and tracheal intubation was facilitated with $0.6 \mathrm{mg} / \mathrm{kg}$ rocuronium. The patients' lungs were ventilated with a tidal volume of 8-10 $\mathrm{ml} / \mathrm{kg}$, with an $\mathrm{I}: \mathrm{E}$ ratio of $1: 2$ at a respiratory rate of $8-12$ breaths $/ \mathrm{min}$ in $50 \%$ oxygen with air to maintain normocarbia throughout the surgery. Anesthesia was maintained with continuous infusion of remifentanil $(0.05-0.2 \mu \mathrm{g} / \mathrm{kg} / \mathrm{min})$, rocuronium (5-6 $\mu \mathrm{g} / \mathrm{kg} / \mathrm{min})$, and sevoflurane (1.8-2\%).

At the end of the surgery (approximately $15 \mathrm{~min}$ before tracheal extubation), patients received either ramosetron or ondansetron according to their allocated group, and intravenous PCA commenced. In group $\mathrm{R}+\mathrm{D}$ patients, ramosetron $0.3 \mathrm{mg}$ was injected, and $0.3 \mathrm{mg}$ was added to the PCA regimen. In group $\mathrm{O}+\mathrm{D}$ patients, ondansetron $4 \mathrm{mg}$ was injected, and $12 \mathrm{mg}$ was added to the PCA regimen. Study medications were prepared by personnel not involved in this study and presented to blinded investigators as identical 2 ml-filled syringes; the PCA syringes were also prepared by the same individuals. The PCA regimen consisted of fentanyl $25 \mu \mathrm{g} / \mathrm{kg}$ (total volume including saline: $100 \mathrm{ml}$ ) and was programmed to deliver $2 \mathrm{ml} /$ $\mathrm{hr}$ as the background infusion and $0.5 \mathrm{ml}$ per demand with a 15 min lockout during the $48 \mathrm{hr}$ postoperative period.

Nausea was defined as a subjectively unpleasant sensation associated with awareness of the urge to vomit. Vomiting was defined as a single episode of the forceful expulsion of gastric contents through the mouth or as an expulsive movement of the stomach muscles without expelled stomach contents. Nausea intensity was graded on a scale of 11 points $(0=$ no nausea, $10=$ worst possible nausea) using verbal rating scales (VRS). A rescue antiemetic, intravenous metoclopramide 10 $\mathrm{mg}$, was given in response to nausea with a VRS score $>4$ at the discretion of the attending physicians blinded to the patients' group assignments, with two or more episodes of vomiting. When nausea more than 7 on VRS and/or vomiting persisted or patients requested more than 2 consecutive boluses of metoclopramide, intravenous PCA was stopped for $2 \mathrm{hr}$. Pain intensity scores were measured on a visual analog scale (VAS; $0=$ no pain, $100=$ maximal pain) ranging from 0 to $100 \mathrm{~mm}$. A patient received ketorolac $30 \mathrm{mg}$ intravenously by request if her pain score exceeded $50 \mathrm{~mm}$ on VAS. 
The occurrence of the most frequent side effects of the $5-\mathrm{HT}_{3}$ antagonists used in conjunction with opioid-based PCA, such as headache, dizziness, and drowsiness, were recorded; adverse effects associated with dexamethasone use, such as increased risk of infection, glucose intolerance, and delayed wound healing, were also assessed throughout the study period.

Sample size estimation was determined based on the ability to detect the difference in the incidence of PONV. With 60 patients in each group, $80 \%$ power at an $\alpha$ of 0.05 was required to detect a $25 \%$ difference in the number of patients with PONV up to $48 \mathrm{hr}$ after surgery. This was based on a pilot study of 40 patients, in which the incidence of PONV was 7 patients (35\%) receiving ramosetron plus dexamethasone and 12 patients $(60 \%)$ receiving ondansetron plus dexamethasone. Statistical analyses were performed with SPSS 18.0 (SPSS Inc., Chicago, IL). All data are expressed as mean \pm standard deviation (SD) or number. Data between the groups were compared using a chisquare test, Fisher exact test, independent t-test, or the MannWhitney $\mathrm{U}$ test, as appropriate. A P value of less than 0.05 was considered to be statistically significant.

\section{Results}

One hundred twenty-five patients were assessed. Two patients treated with steroids within $24 \mathrm{hr}$ before surgery and three patients with impaired renal function were excluded. Patients' characteristics, including history of PONV and/or motion sickness and operative data were similar between the groups. Additionally, no significant differences were observed in the amount of anesthetic agents or narcotics used during operation between the groups. PCA devices were discontinued in 4 patients $(7 \%)$ of group $\mathrm{R}+\mathrm{D}$ and in 6 patients $(10 \%)$ of group $\mathrm{O}+\mathrm{D}$ due to intractable nausea and/or vomiting between 24 and $48 \mathrm{hr}$ after surgery ( $\mathrm{P}=0.509$; Table 1$)$.

Table 1. Patients' Characteristics and Operative Data

\begin{tabular}{lcc}
\hline & $\begin{array}{c}\text { Group R }+\mathrm{D} \\
(\mathrm{n}=60)\end{array}$ & $\begin{array}{c}\text { Group O + D } \\
(\mathrm{n}=60)\end{array}$ \\
\hline Age (yr) & $51 \pm 9$ & $50 \pm 10$ \\
Body mass index $\left(\mathrm{kg} / \mathrm{m}^{2}\right)$ & $24 \pm 3$ & $23 \pm 3$ \\
History of postoperative nausea & $2(3)$ & $4(7)$ \\
$\quad$ and vomiting & $18(30)$ & $15(25)$ \\
History of motion sickness & & \\
Simplified risk score & $41(68)$ & $43(72)$ \\
3 & $19(32)$ & $17(28)$ \\
4 & $166 \pm 55$ & $171 \pm 45$ \\
Anesthesia time (min) & $124 \pm 51$ & $130 \pm 41$ \\
Operation time (min) & $1,370 \pm 140$ & $1,373 \pm 121$ \\
Amount of fentanyl used $(\mu \mathrm{g})$ & $1,025 \pm 266$ & $998 \pm 321$ \\
Crystalloids (ml) & $4(7)$ & $6(10)$ \\
IV PCA discontinuation & & \\
\hline
\end{tabular}

Values are mean \pm SD or numbers $(\%)$.
The incidence of PONV and need for rescue antiemetics were not different between groups throughout the study period. The overall incidence of nausea was similar between groups $\mathrm{R}+\mathrm{D}$ and $\mathrm{O}+\mathrm{D}$ ( $47 \%$ vs. $60 \%$, respectively). The overall incidence of vomiting was also similar between groups $\mathrm{R}+\mathrm{D}$ and $\mathrm{O}+\mathrm{D}(8 \%$ vs. $12 \%$, respectively). The overall use of rescue antiemetic was not different between the groups ( $28 \%$ vs. $20 \%$ ). Nausea severity was similar between the groups (Table 2). The median severity of nausea in the three time periods was as follows [interquartile range (range)]: 0 [0-2.8 $(0-10)]$ vs. $0[0-2(0-9)](\mathrm{P}=0.72) ; 0$ $[0-2(0-10)]$ vs. $0[0-1(0-10)](\mathrm{P}=0.98)$; and $0[0-0.8(0-$ $8)]$ vs. $0[0-0(0-8)](\mathrm{P}=0.603)$ in groups $\mathrm{R}+\mathrm{D}$ and $\mathrm{O}+\mathrm{D}$, respectively.

Pain intensity scores were similar between the groups at $0-6$ $\mathrm{hr}$ and $24-48 \mathrm{hr}$ after surgery. The total amount of ketorolac for rescue analgesia used was not different between group $\mathrm{R}+\mathrm{D}$ and group $\mathrm{O}+\mathrm{D}$ (Table 3$)$.

Table 2. Incidence of Nausea, Vomiting, and Requirement for Rescue Antiemetic Treatment

\begin{tabular}{lccc}
\hline & $\begin{array}{c}\text { Group R }+\mathrm{D} \\
(\mathrm{n}=60)\end{array}$ & $\begin{array}{c}\text { Group O }+\mathrm{D} \\
(\mathrm{n}=60)\end{array}$ & $\mathrm{P}$ \\
\hline Nausea & & & \\
Total & $28(47)$ & $36(60)$ & 0.143 \\
$0-6 \mathrm{hr}$ & $20(33)$ & $24(40)$ & 0.449 \\
$6-24 \mathrm{hr}$ & $20(33)$ & $22(37)$ & 0.702 \\
$24-48 \mathrm{hr}$ & $15(25)$ & $12(21)$ & 0.577 \\
Vomiting & & & \\
Total & $5(8)$ & $7(12)$ & 0.543 \\
$0-6 \mathrm{hr}$ & $3(5)$ & $3(5)$ & 1.0 \\
$6-24 \mathrm{hr}$ & $3(5)$ & $3(5)$ & 1.0 \\
$24-48 \mathrm{hr}$ & $1(2)$ & $2(3)$ & 0.615 \\
PONV & & & \\
Total & $30(50)$ & $36(60)$ & 0.271 \\
$0-6 \mathrm{hr}$ & $21(35)$ & $24(40)$ & 0.572 \\
$6-24 \mathrm{hr}$ & $21(35)$ & $22(37)$ & 0.849 \\
$24-48 \mathrm{hr}$ & $15(25)$ & $12(21)$ & 0.577 \\
Rescue antiemetic & & & \\
Total & $17(28)$ & $12(20)$ & 0.286 \\
$0-6 \mathrm{hr}$ & $10(17)$ & $8(13)$ & 0.609 \\
$6-24 \mathrm{hr}$ & $8(13)$ & $6(10)$ & 0.57 \\
$24-48 \mathrm{hr}$ & $5(8)$ & $5(8)$ & 1.0 \\
\hline
\end{tabular}

Values are numbers (\%).

Table 3. Pain Intensity Scores and Total Rescue Analgesic Doses

\begin{tabular}{lccc}
\hline & $\begin{array}{c}\text { Group R + D } \\
(\mathrm{n}=60)\end{array}$ & $\begin{array}{c}\text { Group O + D } \\
(\mathrm{n}=60)\end{array}$ & $\mathrm{P}$ \\
\hline Pain intensity scores & & & \\
$0-6 \mathrm{~h}$ & $35 \pm 17$ & $39 \pm 13$ & 0.174 \\
$6-24 \mathrm{~h}$ & $35 \pm 19$ & $29 \pm 12$ & 0.053 \\
$24-48 \mathrm{~h}$ & $26 \pm 16$ & $25 \pm 14$ & 0.606 \\
Pain rescue dose (mg) & $82 \pm 43$ & $72 \pm 41$ & 0.192 \\
\hline
\end{tabular}

Values are mean \pm SD. 
Table 4. Side Effects of Antiemetic Drugs

\begin{tabular}{lccc}
\hline & $\begin{array}{c}\text { Group R + D } \\
(\mathrm{n}=60)\end{array}$ & $\begin{array}{c}\text { Group O + D } \\
(\mathrm{n}=60)\end{array}$ & $\mathrm{P}$ \\
\hline Headache & $8(13)$ & $3(5)$ & 0.114 \\
Dizziness & $10(17)$ & $14(23)$ & 0.361 \\
Drowsiness & $4(7)$ & $2(3)$ & 0.679 \\
\hline
\end{tabular}

Values are numbers (\%).

No patient withdrew from the study due to adverse events from the $5-\mathrm{HT}_{3}$ antagonists. The most common adverse effects were headache, dizziness, and drowsiness; no differences were observed in the incidence of these events between the groups during the study period (Table 4). No clinically serious adverse events attributed to dexamethasone were observed in either group.

\section{Discussion}

In this prospective, randomized, double-blind study comparing the antiemetic efficacy of ramosetron plus dexamethasone with that of ondansetron plus dexamethasone in highly susceptible patients using fentanyl-based intravenous PCA during the $48 \mathrm{hr}$ period after lumbar spinal surgery, we could observe that ondansetron plus dexamethasone was as effective as ramosetron plus dexamethasone in reducing the incidence of PONV and the severity of nausea.

In patients following lumbar spinal surgery, effective postoperative pain treatment is important to facilitate early rehabilitation and improve recovery, thus preventing the development of chronic pain syndrome [13]. Although opioid-based intravenous PCA is widely used with a high satisfaction rate for postoperative pain control, the baseline risk for PONV of nonsmoking women receiving opioid-based intravenous PCA is high, reaching about $60 \%$ [3]. In addition, vomiting may cause dehydration, electrolyte imbalance, disruption of the surgical repair, and an increase in the perception of pain, resulting in delayed recovery [14]. To avoid unnecessary prolongation of the hospital stay, it is important not only to reduce pain intensity using an adequate PCA regimen but also to prevent intravenous PCA-related PONV. Therefore, in patients highly susceptible to PONV treated with opioid-based intravenous PCA, multimodal antiemetic prophylaxis should be considered rather than treating the established PONV [2,5].

A variety of $5-\mathrm{HT}_{3}$ antagonists with dexamethasone have been used for prophylaxis of PONV, and their antiemetic efficacies are more beneficial in combination with dexamethasone than alone $[9-12,15,16]$. Dexamethasone, a corticosteroid, has antiemetic properties and acts synergistically with $5-\mathrm{HT}_{3}$ antagonists. The suggested mechanisms for the improved effects of combination therapy are as follows: dexamethasone may inhibit stimulation of $5-\mathrm{HT}_{3}$ receptors by reducing the levels of 5-HT in neural tissue by depleting its precursor tryptophan and preventing serotonin release in the gut; by inhibiting prostaglandin synthesis; and by reducing the ascending parasympathetic impulses to the vomiting center by decreasing tissue inflammation of the surgical sites [17-19]. The antiemetic effect of dexamethasone is similar against both nausea and vomiting, which is more pronounced in the late postoperative period by its prolonged biological half-life of 36 to 72 hours [17]. However, in this study, the addition of dexamethasone with both $5-\mathrm{HT}_{3}$ antagonists eliminated the differences in efficacy between ramosetron and ondansetron, which was observed when each drug was used alone in previous studies $[6,7,20]$. In several studies, ramosetron $0.3 \mathrm{mg}$ was more effective than ondansetron $4 \mathrm{mg}$ for PONV prophylaxis $[6,7,21]$, while ramosetron $0.3 \mathrm{mg}$ was as effective as ondanseton $8 \mathrm{mg}$ in reducing the incidence of PONV and nausea severity $24 \mathrm{hr}$ after gynecological surgery in high-risk patients receiving fentanylbased intravenous PCA [20]. In this study, no difference was seen in the incidence of PONV between the ramosetron $(0.3+$ $0.3 \mathrm{mg}$ ) plus dexamethasone and ondansetron $(4+12 \mathrm{mg})$ plus dexamethasone groups. Since this was a clinical study, we could not clarify the pharmacodynamic interactions of these $5-\mathrm{HT}_{3}$ antagonists with dexamethasone. All $5-\mathrm{HT}_{3}$ antagonists have a similar mechanism of action; they bind competitively and selectively to the $5-\mathrm{HT}_{3}$ receptor in the chemoreceptor trigger zone and the gastrointestinal tract [22]. However, considerable differences exist in receptor affinity and pharmacokinetics, including the elimination of the half-life between ramosetron and ondansetron $(5.8 \pm 1.2 \mathrm{hr}$ vs. $3.8 \pm 1 \mathrm{hr}$, respectively) [23,24] Although the addition of corticosteroids could theoretically obviate the inferiority of the $5-\mathrm{HT}_{3}$ antagonists, the more potent affinity for the $5-\mathrm{HT}_{3}$ receptor would not lead to more synergistic pharmacodynamic results if drugs from different classes partially involve common antiemetic mechanisms [17,18,25]. To our knowledge, little has been done to compare the efficacy of combination therapy with each $5-\mathrm{HT}_{3}$ antagonist and dexamethasone alone, and studies to determine combination therapy mechanisms of action need to be performed.

This study has several limitations. Ramosetron was continuously infused with intravenous PCA by the same methods as delivering ondansetron; however, clinical evidence regarding the pharmacokinetic profile of continuous infusion of ramosetron is still lacking. Although evidence is available on the appropriate dose of dexamethasone as an adjunct to prevent intravenous PCA-related PONV, we selected a relatively small dose to reduce dexamethasone's side effects $[11,16]$. No reports of side effects, such as increased infection risk, glucose intolerance, delayed wound healing, and adrenal suppression associated with the use of a single dose of dexamethasone, were 
noted [17]. In this study, a single dose of $5 \mathrm{mg}$ dexamethasone was not related to these adverse effects.

In conclusion, the antiemetic efficacy of ondansetron plus dexamethasone was similar to that of ramosetron plus dexamethasone in preventing PONV in highly susceptible patients who are receiving fentanyl-based intravenous PCA following lumbar spinal surgery.

\section{References}

1. Habib AS, Chen YT, Taguchi A, Hu XH, Gan TJ. Postoperative nausea and vomiting following inpatient surgeries in a teaching hospital: a retrospective database analysis. Curr Med Res Opin 2006; 22: 1093-9.

2. Gan TJ, Meyer TA, Apfel CC, Chung F, Davis PJ, Habib AS, et al. Society for Ambulatory Anesthesia guidelines for the management of postoperative nausea and vomiting. Anesth Analg 2007; 105: 1615-28.

3. Apfel CC, Läärä E, Koivuranta M, Greim CA, Roewer N. A simplified risk score for predicting postoperative nausea and vomiting: conclusions from cross-validations between two centers. Anesthesiology 1999; 91: 693-700.

4. Fisher CG, Belanger L, Gofton EG, Umedaly HS, Noonan VK, Abramson C, et al. Prospective randomized clinical trial comparing patient-controlled intravenous analgesia with patient-controlled epidural analgesia after lumbar spinal fusion. Spine (Phila Pa 1976) 2003; 28: 739-43.

5. Apfel CC, Korttila K, Abdalla M, Kerger H, Turan A, Vedder I, et al. A factorial trial of six interventions for the prevention of postoperative nausea and vomiting. N Engl J Med 2004; 350: 2441-51.

6. Choi YS, Shim JK, Yoon do H, Jeon DH, Lee JY, Kwak YL. Effect of ramosetron on patient-controlled analgesia related nausea and vomiting after spine surgery in highly susceptible patients: comparison with ondansetron. Spine (Phila Pa 1976) 2008; 33 : E602-6.

7. Hahm TS, Ko JS, Choi SJ, Gwak MS. Comparison of the prophylactic anti-emetic efficacy of ramosetron and ondansetron in patients at high-risk for postoperative nausea and vomiting after total knee replacement. Anaesthesia 2010; 65: 500-4.

8. Fujii Y, Tanaka H, Kawasaki T. Benefits and risks of granisetron versus ramosetron for nausea and vomiting after breast surgery: a randomized, double-blinded, placebo-controlled trial. Am J Ther 2004; $11: 278-82$.

9. Biswas BN, Rudra A. Comparison of granisetron and granisetron plus dexamethasone for the prevention of postoperative nausea and vomiting after laparoscopic cholecystectomy. Acta Anaesthesiol Scand 2003; 47: 79-83.

10. Janknegt R, Pinckaers JW, Rohof MH, Ausems ME, Arbouw ME, van der Velden RW, et al. Double-blind comparative study of droperidol, granisetron and granisetron plus dexamethasone as prophylactic anti-emetic therapy in patients undergoing abdominal, gynaecological, breast or otolaryngological surgery.
Anaesthesia 1999; 54: 1059-68.

11. Coloma M, White PF, Markowitz SD, Whitten CW, Macaluso AR, Berrisford SB, et al. Dexamethasone in combination with dolasetron for prophylaxis in the ambulatory setting: effect on outcome after laparoscopic cholecystectomy. Anesthesiology 2002; 96: 134650.

12. Elhakim M, Nafie M, Mahmoud K, Atef A. Dexamethasone $8 \mathrm{mg}$ in combination with ondansetron $4 \mathrm{mg}$ appears to be the optimal dose for the prevention of nausea and vomiting after laparoscopic cholecystectomy. Can J Anaesth 2002; 49: 922-6.

13. Bonnet F, Marret E. Postoperative pain management and outcome after surgery. Best Pract Res Clin Anaesthesiol 2007; 21: 99-107.

14. Jellish WS, Leonetti JP, Sawicki K, Anderson D, Origitano TC. Morphine/ondansetron PCA for postoperative pain, nausea, and vomiting after skull base surgery. Otolaryngol Head Neck Surg 2006; 135: 175-81.

15. Gan TJ, Coop A, Philip BK. A randomized, double-blind study of granisetron plus dexamethasone versus ondansetron plus dexamethasone to prevent postoperative nausea and vomiting in patients undergoing abdominal hysterectomy. Anesth Analg 2005; 101: 1323-9.

16. Paech MJ, Rucklidge MW, Lain J, Dodd PH, Bennett EJ, Doherty DA. Ondansetron and dexamethasone dose combinations for prophylaxis against postoperative nausea and vomiting. Anesth Analg 2007; 104: 808-14.

17. Henzi I, Walder B, Tramèr MR. Dexamethasone for the prevention of postoperative nausea and vomiting: a quantitative systematic review. Anesth Analg 2000; 90: 186-94.

18. Fredrikson M, Hursti T, Fürst CJ, Steineck G, Börjeson S, Wikblom M, et al. Nausea in cancer chemotherapy is inversely related to urinary cortisol excretion. Br J Cancer 1992; 65: 779-80.

19. Wang JJ, Ho ST, Uen YH, Lin MT, Chen KT, Huang JC, et al. Smalldose dexamethasone reduces nausea and vomiting after laparoscopic cholecystectomy: a comparison of tropisetron with saline. Anesth Analg 2002; 95: 229-32.

20. Kim SI, Kim SC, Baek YH, Ok SY, Kim SH. Comparison of ramosetron with ondansetron for prevention of postoperative nausea and vomiting in patients undergoing gynaecological surgery. Br J Anaesth 2009; 103: 549-53.

21. Ryu J, So YM, Hwang J, Do SH. Ramosetron versus ondansetron for the prevention of postoperative nausea and vomiting after laparoscopic cholecystectomy. Surg Endosc 2010; 24: 812-7.

22. Bunce KT, Tyers MB. The role of 5 -HT in postoperative nausea and vomiting. Br J Anaesth 1992; 69(7 Suppl 1): 60S-2S.

23. Kawabata Y, Sakiyama H, Muto S. Clinical evaluation and pharmacokinetics of ramosetron against the nausea and vomiting induced by anticancer drugs. Nishinihon J Urol 1994; 56: 1445-56.

24. Roila F, Del Favero A. Ondansetron clinical pharmacokinetics. Clin Pharmacokinet 1995; 29: 95-109.

25. Suzuki T, Sugimoto M, Koyama H, Mashimo T, Uchida I. Inhibitory effect of glucocorticoids on human-cloned 5-hydroxytryptamine3A receptor expressed in xenopus oocytes. Anesthesiology 2004; 101: 660-5. 